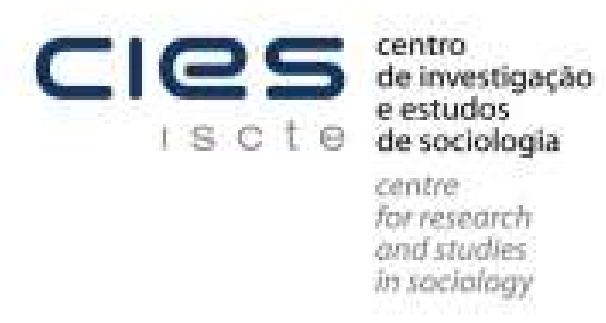

CIES e-WORKING PAPER N. ${ }^{\circ}$ 74/2009

\title{
Youth on the move? Student mobility and immobility in Portugal and Northern Ireland
}

\author{
DAVID CAIRNS
}

CIES e-Working Papers (ISSN 1647-0893)

Av. das Forças Armadas, Edifício ISCTE, 1649-026 LiSBOA, PORTUGAL, cies@iscte.pt 
David Cairns has been a researcher at the Centre for Research and Studies in Sociology since May 2009. Previously, he was a Senior Research Associate in the Institute of Social Sciences at the University of Lisbon for three years. He has also worked and studied at the National University of Ireland, Galway, Queen's University Belfast and the University of Ulster. Research activities undertaken include a study of youth and geographical mobility (2005-2008), the European Commission funded study Families and Transitions in Europe (2001-2005), and a doctoral thesis exploring sectarianism in Northern Ireland. His main research interests are in the areas of youth and migration, in particular from comparative European perspectives, with over twenty publications to date, including articles in International Migration, Journal of the Royal Anthropological Institute and Young. E-mail: david.cairns@iscte.pt

\begin{abstract}
This paper provides insight into the geographical mobility experiences and orientations of youth in Portugal and Northern Ireland, utilising the results of quantitative and qualitative research conducted during 2005-2008. An overview is presented of the past mobility experiences of two academically matched groups of students in Lisbon and Belfast, followed by indications of future mobility intentions, including transnational migration. The main findings are that while a majority of those sampled in Belfast (55\%) have intentions to live outside Northern Ireland at some stage in the future, fewer of their counterparts in Lisbon have such a desire (32\%). Further logistic regression analysis explores the extent to which social ties impact upon the direction of future migration intentions, while results are less supportive of economic explanations for wanting to move. The results related to economic explanations for the desire to move confirm other research results, while contradicting neo-classical thinking.
\end{abstract}

Key-words: youth, geographical mobility, Portugal, Northern Ireland 


\section{Introduction}

"Why do people move from one country or region to another?" is a key question in migration studies. Besides this enquiry, we might be equally interested in finding out why other people do not move and elect to live out their whole lives within the confines of one particular local community, geographical region or nation state. While explorations of adults' motivations for migration are relatively commonplace (see, for example, Hadler, 2006), we know less about young people's motivations for transnational movements or the lack of them. The reasons why youth has been neglected in accounts of population movements are not clear and the absence of youth in migration theory is striking (see, for example, Cohen 1995; Brettell and Hollifield 2000; Pappastergiadis 2000). Statistical evidence on young people's movements, particularly between different European member states, is also hard to find. The few studies which do address youth migrations concentrate principally upon evaluating officially mediated student mobility programmes, e.g. Erasmus-Socrates, as opposed to considering the individually inspired actions of free movers (King 2002; King and Ruis-Gelices 2003; Baláž and Williams 2004; Findlay et al. 2006). This paper aims to address this knowledge gap and explore why young people are, and are not, on the move, concentrating upon European youth.

\section{Methodology}

The original research upon which this paper is based formed part of a research project entitled "Culture, Youth and Future Life Orientations". The aim of this project, conducted during the period 2005-2008, was to examine the future life plans of highlyskilled and well-qualified European young people, particularly in respect to geographical mobility. In the course of this research, young people were surveyed in two different geographical contexts: Northern Ireland and Portugal. The choice of these two locations was in part inspired by prior research by the author, which revealed that out of nine different European regions Portugal had the least geographically mobile young people and Northern Ireland some of the most, making for a potentially interesting contrast (see Biggart and Cairns 2004). This choice was also due to more pragmatic reasons, such as budgetary and time constraints. Both these regions however 
have a number of commonalities, such as strong historical traditions of migration, and occupy geographically peripheral positions in the European Union.

This project entailed undertaking both quantitative and qualitative investigation. In sampling, focus was placed upon gathering data from university students. This was due to young people at third level educational institutions having a greater potential to be mobile, or at least to contemplate mobility during the education-to-work transition, compared to their younger contemporaries in secondary and post-secondary education and those already settled in their careers (King and Ruis-Gelices 2003). In the quantitative research phase, a questionnaire was administered to a total of 250 young people in Northern Ireland, all of whom studied at universities in and around the Belfast area, and 200 young people in Portugal, specifically those at university institutions in Lisbon. In each case, these respondents were taken from classes across four different academic disciplines: Arts and Humanities, Social Sciences, Science and Engineering. These samples were also balanced in terms of gender and the inclusion of ethnic minorities. ${ }^{1}$ For the qualitative part of this study a total of 15 follow-up interviews were conducted with respondents in each region, all of whom were sourced from the initial quantitative samples. These interviews were semi-structured, consisting of initial questions regarding mobility orientations and experiences, followed by more in-depth biographical discussion of specific life events and plans, such as time spent working or studying abroad and future mobility intentions.

\section{Analysis}

To return to the main research questions, the following analysis and discussion of results is focused not only upon ascertaining the extent to which youth are, or are not, on the move, but also attempting to provide possible explanations of the mobility orientations on display within the two samples. Quantitative breakdowns provide information on the current prevalence of mobility among the youth surveyed, complemented by an examination of future migration intentions within the two samples. This initial analysis is followed by a more in-depth statistical exploration of migration decision-making

1 A deliberate decision was taken, however, not to include students from courses in which geographical mobility is mandatory, such as languages, which means that this is a study of "optional" movements (Findlay et al. 2006: 300). 
using binary logistic regression procedures, in an attempt to move towards a better understanding of youth mobility. ${ }^{2}$

\subsection{Past Mobility Experiences}

The following descriptive breakdowns provide indications of both present levels of transnational mobility and anticipated future migration intentions among those surveyed in both regional contexts. In respect to current prevalence, the following table provides an overview of the popularity of travel outside the country of origin, including gender breakdowns.

Table 1 Travel outside Country of Origin in last 12 months by Region and Gender

\begin{tabular}{llcc}
\hline Region & Gender & $\begin{array}{c}\text { Travel outside Country of } \\
\text { Origin? (\%) }\end{array}$ & \\
\hline \multirow{3}{*}{ Belfast } & Male & Yes & No \\
& Female & 84 & 16 \\
& All & 80 & 20 \\
\hline \multirow{3}{*}{ Lisbon } & & 82 & 18 \\
& Male & & 45 \\
\hline & Female & 55 & 60 \\
\hline
\end{tabular}

Pearson chi-square level of significance $=.479$ (Belfast), .026 (Lisbon)

From this table, we can make two interesting observations: that the Belfast young people register a much greater frequency of travel outside their country of origin compared to their Portuguese peers and that, in the Lisbon sample, there is a significant gender dichotomy, with young males undertaking more international travel than the young females in the sample. Reasons for the gender difference are unclear but, regarding the differences between the samples, it may be the case that Portuguese youth are more likely to be holidaying at home. The Northern Ireland young people are less

2 A more in-depth discussion of these results, including elaboration of the qualitative case studies, can be found in Cairns (2008), Cairns (2009) and Cairns and Smyth (2009). 
likely to do so due to factors such as the more temperate Irish climate, the lack of alluring destinations near at hand and the relatively high cost of holidaying at home compared to foreign destinations such as Spain and Greece.

Table 2 Main Reason for Travel outside Country of Origin in last 12 months by Region and Gender

\begin{tabular}{llccccr}
\hline Region & Gender & $\begin{array}{c}\text { Main } \\
\text { Reason for } \\
\text { Travel (\%) }\end{array}$ & & & & \\
& & Leisure & Family & Work & Study & Char \\
\hline Belfast & Male & 65 & 7 & 8 & 15 & 5 \\
& Female & 77 & 8 & 4 & 8 & 3 \\
& All & 71 & 8 & 6 & 11 & 4 \\
& & & & & & 12 \\
Lisbon & Male & 75 & 10 & 2 & 2 & 0 \\
& Female & 83 & 13 & 2 & 8 & 0
\end{tabular}

While Table 1 appears to indicate that many young people undertake a substantial amount of transnational movement, we need to consider their motivations and justifications for this travel. The most obvious outcome in Table 2 is the significance of travel for leisure purposes in both samples: more so for the young Portuguese respondents and for young females in both regions.

The low numbers working abroad can be explained by the fact that these young people are still studying. If the summer bar jobs abroad undertaken by a number of Belfast (mostly male) respondents are discounted, studying abroad was not so common, although the higher numbers of young Portuguese males doing so is curious. A small number of those included in the Belfast sample had also travelled for charitable purposes, including church and voluntary work, while no one in the Lisbon sample had done so.

After consideration of the current prevalence of transnational movement among these two groups of young people and the largely leisure-orientated nature of this movement, of further interest are future intentions to live outside the country of origin (Table 3). 
Table 3 Intention to Live Outside Country of Origin by Region and Gender

\begin{tabular}{llcc} 
Region & Gender & $\begin{array}{c}\text { Live Outside Country of } \\
\text { Origin? (\%) }\end{array}$ \\
& & Yes & No \\
\multirow{3}{*}{ Belfast } & Male & 60 & 40 \\
& Female & 51 & 49 \\
\hline \multirow{3}{*}{ Lisbon } & All & 55 & 45 \\
& Male & 35 & 65 \\
& Female & 30 & 70 \\
\hline
\end{tabular}

Pearson chi-square level of significance $=.170$ (Belfast), .530 (Lisbon)

That these are measurements of intentions rather than actions already taking place should be considered in interpreting results. We can however observe that the majority of those surveyed in Belfast (55\%) see themselves living abroad in the future but only a minority in Lisbon (32\%) feel the same way, with no significant gender differences in either region. ${ }^{3}$ This is a major contrast and there are undoubtedly reasons specific to each context which account for the desire or disinclination to move. They are explored in the remaining part of this analysis.

\subsection{What Influences Youth Mobility Decision-Making?}

What remains to be explored in this analysis are the influences upon mobility decisionmaking, including migration to other countries. The most obvious answer is the neoclassical economic explanation: young people move to pursue better career opportunities and/or to escape what may be difficult financial circumstances at home. This common-sense explanation, referred to by Malmberg as the "traditional push-pull model" (1997: 29), dominates much thought and discussion in public, policy and academic discourse on migration - to the extent that it is often assumed that it is the only explanation, with the relationship between money and movement being a simple

3 Further analysis also revealed that there was no clear linear relationship between a higher or lower age and the wish to be mobile in either of the two research contexts. 
case of cause and effect: a lack of the former leads to pursuit of the latter. It is therefore tempting to assume that migration is only a matter of money and nothing more.

It would indeed be unwise to discount the importance of finance and better earning opportunities in migration decision-making. However to assume that such a personal and potentially life changing option can be reduced to simple economics is rather simplistic. This model also assumes that migrants have accurate and detailed information on the economic situations both in their countries of origin and imagined host societies, or "costless access to perfect information" (Fisher et al. 1997: 54), and that "a rational economic calculation" has taken place (Malmberg, 1997: 29). This is not entirely credible, considering both the distorted views we often have of living conditions in societies other than our own, and even of our own, and the typically chaotic nature of actual migratory movements.

Of equal importance to this debate is the fact that the neo-classical economic approach fails to appreciate the complexity of the migration decision, which will inevitably entail not only individual differences (Fisher et al. 1997: 55) but also considerations connected with one's family, friends and other community ties, i.e. social relationships and social capital, as well as one's occupation and bank balance. The impact of finance on migration may also be diffuse, with people either moving away from poverty and towards wealth or making a move because they have the financial resources to do so. Therefore, while we should not neglect economics, we should consider a range of different influences on the youth's mobility decisions.

One means of exploring the possible validity of the economic explanation is to look at the relationship between socio-economic background, as derived from parental occupation, and youth mobility intentions, ${ }^{4}$ with the assumption that those from less affluent backgrounds will be more likely to want to move.

\footnotetext{
4 Socio-economic status was unknown for $6 \%$ of the Belfast respondents and $25 \%$ of the Lisbon respondents due to parents being economically inactive. This was due in most part to parental unemployment or one or both parents being deceased, although in Lisbon, a much greater proportion of young people indicated that they had mothers who did not work outside the home.
} 
Table 4 Intention to Live Outside Country of Origin by Region and Socio-economic Background

Region Socio-economic Background

Belfast

Lisbon

Skilled Non-Manual

Skilled Manual

Semi-/Unskilled Non-Manual

Semi-/Unskilled Manual

Service

All
Live Outside

Country of Origin

$(\%)$

Yes $\quad$ No

$54 \quad 46$

$51 \quad 49$

$69 \quad 31$

$54 \quad 46$

$60 \quad 40$

$54 \quad 46$

These outcomes reveal no clear trends. The Lisbon data is inconclusive, although none of the young people from "Semi-/Unskilled Manual" backgrounds in the Lisbon sample registered mobility intentions. In the Belfast sample, we might deduce from these figures that those from "Non-Manual" backgrounds are more likely to be considering mobility. Furthermore, we can see that the higher proportions among those from "Semi/Unskilled Non-Manual" backgrounds is consistent with the idea of the less affluent being more likely to want to move. However, the small sample sizes, particularly for the Lisbon youth, limit what we can read into these results.

Regarding more subjective economic measures, as part of the quantitative survey, respondents were asked a number of key questions regarding perceptions of their country's recent economic performance. One particularly interesting outcome concerned the acceptability of local salary levels. In Belfast, it was found that those who thought local salary levels too low were more likely to be considering living abroad (58\%) but 
not to a significantly higher degree/level than those who thought otherwise (47\%); neither was there a correlation between fear of unemployment in Belfast and wanting to move, with $49 \%$ of those with such anxiety planning to move and $53 \%$ planning not to.

Meanwhile in Lisbon, $72 \%$ of those considering living abroad in the future agreed that salaries are too low in Portugal but $87 \%$ of those not considering transnational mobility also thought so. The difference here is certainly significant (Pearson chi-square level of significance .013) but not suggestive of migration being linked to perceptions of relatively low salaries at home but rather of low wages at home militating against transnational mobility. In relation to the fear of unemployment in Lisbon, the trend found in the Belfast sample, that those planning to stay were more likely to register anxiety $(80 \%)$ than those contemplating leaving (68\%), was more pronounced, though this was not a statistically significant difference.

The weakness of the "economic" evidence in accounting for the decision to move among the youth population, or at least for the argument that potential poverty incubates a desire to move, means we need to look elsewhere for answers. As we have seen, however, finance may play an important role in explaining immobility, although this is a debate which requires further exploration in its own right. In accounting for mobility, it may also be the case that personal factors such as the influence of family and friends are more salient than economic considerations (Malmberg 1997: 41).

The impacts of family and peer relationships, along with prevailing social norms within local communities, are explored in the following series of separate binary logistic regression analyses of the responses made to various statements in the quantitative survey questionnaire. All of these breakdowns utilise/use the intention to be mobile as the dependent variable. 
Table 5 Statements on Family Life by Region and Intention to be Mobile

Statement

My family would understand if I had to leave home to find a good job

I have siblings who left home to live in other countries

I have siblings who left home to live in other parts of my country

My family need me to support them

I need my family to support me

Having a good family life is more important than having a good job

Most of my family live near me

It's good to live at home with your parents

I would feel incomplete without my family

\begin{tabular}{lcc} 
Region & $\beta$ & Exp (ß) \\
Belfast & .773 & 2.167 \\
Lisbon & .802 & 2.231 \\
Belfast & .662 & $1.938^{*}$ \\
Lisbon & 1.171 & $3.224^{*}$ \\
Belfast & .205 & 1.228 \\
Lisbon & .533 & 1.703 \\
Belfast & .138 & 1.148 \\
Lisbon & -.138 & .871 \\
Belfast & -.156 & .855 \\
Lisbon & -.380 & .684 \\
Belfast & -.466 & .628 \\
Lisbon & -.238 & .788 \\
Belfast & -.696 & $.498^{*}$ \\
Lisbon & -.753 & $.471^{*}$ \\
Belfast & -1.017 & $.368^{*}$ \\
Lisbon & .116 & 1.123 \\
\hline Belfast & -1.282 & $.278^{*}$ \\
\hline Lisbon & -.683 & $.505^{*}$ \\
\hline
\end{tabular}

Pearson chi-square level of significance less than $.005 * /=.000 * *$

Table 5 presents an overview of responses made to statements on family life. We can immediately observe a number of possibly encouraging/motivating/positive influences on mobility decision-making and other factors which have a negative impact. Potentially mobile young people are more likely to have understanding families, particularly in the Lisbon sample, with siblings who have left home to live in other countries. We can also observe that the mobility-seeking young people are less likely to feel "incomplete" without "my family" or to live close to most of their family members. 
Table 6 Statements on Peer Relationships by Region and Intention to be Mobile

\begin{tabular}{|c|c|c|c|}
\hline Statement & Region & $\beta ß$ & $\operatorname{Exp}(ß)$ \\
\hline \multirow[t]{2}{*}{ I have friends who live in other countries } & Belfast & .737 & $2.091 *$ \\
\hline & Lisbon & .639 & 1.894 \\
\hline \multirow[t]{2}{*}{ I have friends who live other parts of my country } & Belfast & .354 & 1.424 \\
\hline & Lisbon & .644 & 1.904 \\
\hline \multirow{2}{*}{$\begin{array}{l}\text { Having good friends is more important than having a good } \\
\text { job }\end{array}$} & Belfast & .078 & 1.081 \\
\hline & Lisbon & -.256 & .788 \\
\hline \multirow{2}{*}{$\begin{array}{l}\text { My friends would understand if I went to live in another } \\
\text { country }\end{array}$} & Belfast & .072 & 1.075 \\
\hline & Lisbon & .798 & 2.212 \\
\hline \multirow[t]{2}{*}{ I would feel incomplete without my friends } & Belfast & -.048 & .954 \\
\hline & Lisbon & -.644 & .525 \\
\hline \multirow{2}{*}{$\begin{array}{l}\text { I have many of the same friends today as I did when I was } \\
\text { a child }\end{array}$} & Belfast & -.059 & .943 \\
\hline & Lisbon & -.255 & .775 \\
\hline \multirow{2}{*}{$\begin{array}{l}\text { My friends would understand if I went to live in another } \\
\text { part of my country }\end{array}$} & Belfast & -.123 & .884 \\
\hline & Lisbon & .355 & 1.426 \\
\hline \multirow[t]{2}{*}{ Most of my friends live near me } & Belfast & -.256 & .775 \\
\hline & Lisbon & -.644 & $.525^{*}$ \\
\hline \multirow{2}{*}{$\begin{array}{l}\text { I see myself having many of the same friends in the future } \\
\text { as I have today }\end{array}$} & Belfast & -.531 & .588 \\
\hline & Lisbon & -.233 & .800 \\
\hline
\end{tabular}

Table 6 provides an opportunity to observe responses to a number of statements on various dimensions of peer relationships in relation to plans for future geographical mobility. The results are somewhat inconclusive. Some apparent differences exist between the two samples: for instance, the Lisbon mobility seekers are more likely to have friends who would understand if they went to live in another country and less likely to feel "incomplete" without their friends or to live close to them compared to their contemporaries in Belfast. Generally, these dichotomies are not statistically significant, though there are two exceptions: the potentially mobile in the Belfast sample are significantly more likely to have friends living in other countries, while the Lisbon mobility seekers are significantly less likely to live close to their friends. But generally we can conclude that the influence of peers may not be as important as family in mobility decision-making for either the Belfast or Lisbon respondents. 
Table 7 Statements on Community Attachments by Region and Intentions to be Mobile

\begin{tabular}{llcc} 
Statement & Region & $\beta$ & Exp (ß) \\
I feel more European than Portuguese/Northern Irish & Belfast & 1.022 & $2.780^{*}$ \\
I don't like the area I live in & Lisbon & .393 & 1.481 \\
& Belfast & .738 & $2.092^{*}$ \\
I support my local football team & Lisbon & .373 & 1.453 \\
& Belfast & -.114 & .892 \\
I always vote in elections & Lisbon & -.616 & .540 \\
I regularly go to church & Belfast & -.182 & .834 \\
I regularly socialise in my own area & Lisbon & -.537 & .585 \\
I would not consider having a relationship with someone & Belfast & -.529 & $.589 *$ \\
from another country if it meant having to leave my & Lisbon & .541 & 1.717 \\
country & Belfast & -1.116 & $.455^{*}$ \\
I always want to live in my area & Lisbon & -.477 & .593 \\
\hline
\end{tabular}

Pearson chi-square level of significance less than $.005 * /=.000 * *$

Relationships between responses made to various statements on community attachments and the intention to be mobile are explored in Table 7. There are some extremely significant outcomes in terms of dichotomies between the potentially mobile and immobile and also some regionally specific orientations. Mobility seekers are revealed to be significantly more likely to feel European in Northern Ireland and dislike the areas they live in; romance is also important as they are more likely to consider having a relationship with someone even if it meant leaving their own country; they are also less likely to feel at home in their country of origin, much more so in Northern Ireland, socialise near where they live and, somewhat predictably, want to leave their present area of residence.

The outcomes to these three different sets of statements are open to interpretation due to the subjectivity of these young people's self-evaluations. What constitutes feeling 
"incomplete" without family or peers is certainly debatable and ideas of being "at home" may differ greatly according to personal circumstances. We are however beginning to obtain a more cogent/complete/consistent idea of what differentiates/distinguishes potentially mobile and immobile youth and can see that families and other local community ties have a bearing upon youth mobility orientations as well as, or more so than, the mathematics of their finances. This outcome should not come as any great surprise to those familiar with the complex and often contradictory influences upon young people studying at university, particularly those still living at home (see Cairns and Growiec, 2008).

Having two regional samples, we can observe some cultural differences within Europe, e.g. more dissatisfaction with life and local identities in Northern Ireland and greater economic disillusionment in Portugal. But there are also common experiences, most prominently the shared importance of family in mediating mobility decisionmaking. This may take the form of offering support and understanding to those who wish to leave or of parents sufficiently detaching themselves from their children to enable them to make an exit. It is therefore important that we understand the role of family and local communities when seeking to appreciate why young people are, or are not, planning to be geographically mobile.

\section{Conclusion}

From the evidence presented above, we have gained some interesting/useful insights into the mobility habits and aspirations of these two samples of young people, from Belfast and Lisbon. We can see that while these particular student respondents share an apparent liking for travel, actual movements undertaken are largely for leisure purposes rather than work or study. In respect to transnational mobility in the future, we can observe that there is greater interest in living abroad among those surveyed in Northern Ireland than their Portuguese counterparts.

Considering that the former region is more affluent than the latter country, e.g. in terms of average incomes, this outcome is inconsistent with neo-classical economic thinking. It is however consistent with the results of Hadler's (2006) study of adults' intentions to migrate, as reported in Eurobarometer 54.2 (2001), which found the explanatory power of macro-level variables to be low compared to that of individual 
characteristics. Likewise, in the present context, results make more sense when we consider personal cultural variables. Identification with Northern Ireland is weaker among its tertiary educated youth, which makes it easier to leave, while family bonds are tighter in Portugal, which makes it harder to contemplate making an exit. ${ }^{5}$

These results certainly suggest that family relationships and community attachments play significant roles in helping to shape mobility orientations, while the impact of broader economic factors, including familial affluence, is less clear. The outcomes discussed are obviously most pertinent to the two research contexts in question and represent only an overview of mobility intentions at a particular moment in the life course, namely when young people are making the transition to adulthood. But much still emerges that is of relevance to other places and youth populations, most notably, the need to take into account family influences, community attachments and personal pre-dispositions when examining geographical mobility. This study should therefore be looked upon not only as a statement on youth on the move and youth not on the move but also as a signpost towards an understanding of the phenomenon.

\section{References}

Baláž, Vladimír and Williams, Alan, M (2004): "Been There Done That": International Student Migration and Human Capital Transfers from the UK to Slovakia. Population, Place and Space 10. 217-237.

Biggart, Andy and Cairns, David (2004): Families and Transitions in Europe: Comparative Report. Coleraine: University of Ulster.

Brettell, Caroline B.and Hollifield, James F. (eds) (2000): Migration Theory: Talking Across Disciplines. London: Routledge.

Cairns, David (2008): Moving in Transition: An Exploration of Northern Ireland Youth and Geographical Mobility. Young 16(3). 227-249.

Cairns, David (2009): “The Wrong Portuguese?” in Fassman, H., M. Haller and D. Lane (eds), Migration and Mobility in Europe: Trends, Patterns and Control. Aldershot: Edward Elgar. 103-114.

5 The dependency of Portuguese youth upon their parents has been discussed in terms of the constitution of a "welfare family". See, for example, Pais (1995) and Pappámikail (2004). 
Cairns, David and Growiec, Katarzyna (2008): "I always need my mum": Social Capital and Student Housing Transitions in Northern Ireland. Unpublished conference paper presented at BSA Youth Study Group / University of Teesside Youth Research Group, September 2008.

Cairns, David and Smyth, Jim (2009): "I don't know about living abroad": Exploring Student Mobility and Immobility in Northern Ireland. International Migration 47(4).

Castles, Steven and Miller, Mark J. (1993): The Age of Migration: International Population Movements in the Modern World. Houndmills: Macmillan.

Cohen, Robin (ed.) (1995): The Cambridge Survey of World Migration. Cambridge: University Press.

Findlay, Alan, King, Russell, Stam, Alexandra and Ruiz-Gellices, Enric (2006): Ever Reluctant Europeans. The Changing Geographies of UK Students Studying and Working Abroad. European Urban and Regional Studies 13. 291-318.

Fisher, Peter, Martin, Reiner and Straubhaar, Thomas (1997): Should I Stay or Should I Go? In Thomas Hammar, Grete Brochmann, Kristof Tomas and Thomas Faist (eds), International Migration, Immobility and Development. Multidisciplinary Perspectives, Berg: Oxford. 21-48.

Hadler, Markus (2006): Intentions to Migration Within the European Union: A Challenge for Simple Economic Macro-Level Explanations. European Societies 8(1): 111-140.

King, Russell (2002): Towards a new map of European migration. International Journal of Population Geography 8. 89-106.

King, Russell and Ruiz-Gelices, Enric (2003): International student migration and the European year abroad: effects on European identity and subsequent migration behaviour. International Journal of Population Geography 9. 229-252.

Malmberg, Gunnar (1997): Time and Space in International Migration. In Thomas Hammar/ Grete Brochmann/ Kristof Tomas/ Thomas Faist (eds), International Migration, Immobility and Development. Multidisciplinary Perspectives, Berg: Oxford. 21-48.

Pais, José Machado (1995): Growing Up on the EU Periphery: Portugal. In P. Büchner, $\mathrm{H}-\mathrm{H}$. Krüger, and $\mathrm{M}$ du Bois-Reymond (eds), Growing Up in Europe: Contemporary Horizons in Childhood and Youth Studies. Berlin/New York: de Gruyter.

Pappámikail, Lia (2004): Intergenerational relationships, family support and the transition of young people to adult life in Portugal. Sociologia, Problemas e Prácticas 47.

Pappastergiadis, Nikos (2000): The Turbulence of Migration: Globalization, Deterritorialization and Hybridity. Cambridge: Polity. 